\title{
Initial progress and possible improvement of e-cutter linear actuator development
}

\begin{abstract}
Currently, palm oil has become the most consumed vegetable oil type. This is due to an awareness of the effect Trans Fat has on human health. Therefore, increasing productiveness is a crucial factor to ensure its continued availability as a product in the marketplace. One of the processes that should be improved to increase productivity is harvesting. The Malaysian Palm Oil Board (MPOB) has put a lot of effort into developing a mechanized harvesting tool called the Cantas $\hat{E}$. This efficient tool has been shown to increase oil palm harvesting productivity by a factor of 3 . However, Cantas $\hat{E}$ is ineffective at harvesting oil palm fruit in trees taller than $8 \mathrm{~m}$. Therefore, a new tool called the E-Cutter was introduced. In this paper, the development progress of specifically the E-Cutterô linear actuator part was discussed. The previous type of linear actuator for the E-Cutter is also mentioned. Improvement in the planning and design target of the linear actuator is also addressed. The potential linear actuator structure and type is also identified.
\end{abstract}

Keyword: Component; CantasÊE ; E-cutter; Permanent magnet generator; Slot type linear actuator 